ORIGINAL PROF-2057

\title{
ALVARADO SCORE;
}

Validity in diagnosing acute appendicitis

\section{Dr. Shafaqat Ali, Dr. Zaka Ullah Malik, Dr. M. Muttahhar Asim Niaz, Dr. Naveed Ahmed}

ABSTRACT... Objective: To determine the validity of Alvarado score in diagnosing acute appendicitis keeping histopathology of appendix as gold standard. Study Design: Cross sectional (Validation) study. Place and Duration of Study: Department of Surgery Combined Military Hospital Rawalpindi from April 2009 to October 2009. Materials and Methods: 90 patients with clinical suspicion/diagnosis of acute appendicitis were included in study. All were divided into two groups on the basis of Alvarado score. Group I with score 7-10, who underwent open appendicectomy. Group II(a) with 5-6, who were observed in hospital. Group II(b) with $<4$ were discharged. In all operated cases appendix was sent for histopathology. Alvarado score was compared with histopathology (gold standard). Results: Male to female ratio was 3.5 :1. Mean age was 25.34. Alvarado score had overall $88.13 \%$ sensitivity, $70.96 \%$ specificity, $85.24 \%$ PPV, 75.86\%NPV and $16.90 \%$ negative appendicectomy rate. Whereas in male patients it had $90.74 \%$ sensitivity, $75 \%$ specificity, $92.45 \%$ PPV, $70.58 \%$ NPV and $6.89 \%$ negative appendicectomy rate. In female it had $60 \%$ sensitivity, $66.66 \%$ specificity, $37.5 \%$ PPV, $83.33 \%$ NPV and $38.46 \%$ negative appendicectomy rate. Conclusion: Alvarado score is very accurate for acute appendicitis in male patients. Patients with score 4 can safely be discharged home. USG should be performed routinely in female patients to improve the diagnostic accuracy of Alvarado score.

Key words: Acute appendicitis, Alvarado score, Validity

\section{Article Citation}

$\checkmark \quad$ Ali S, Malik Z, Niaz MMA, Ahmed N. Validity of alvarado score in diagnosing acute appendicitis. Professional Med J Feb 2013;20(1):001-005.

\section{INTRODUCTION}

Acute appendicitis is the most common surgical emergency ${ }^{1}$. Individual life time risk of developing acute appendicitis is approximately $8.6 \%, 6.7 \%$ among males and females respectively ${ }^{2}$. Its recommended treatment is appendicectomy which is the most commonly performed emergency abdominal operation ${ }^{3}$.

Although acute appendicitis is a clinical diagnosis, atypical presentations are common. The efficient approach to diagnose acute appendicitis continues to be surgical challenge ${ }^{4}$. Diagnostic delay has been associated with increased rate of complications, associated cost and lost patients working hours ${ }^{4}$. Mortality rate is $0.2-0.8 \%$ which rises above $20 \%$ in patients older than 70 years primarily because of diagnostic and therapeutic delay.

To avoid morbidity and mortality associated with diagnostic delay surgeons have traditional approach to operate when the diagnosis is probable rather than wait until it is certain. Clinical decision leads to removal of normal appendix in 20-40\% ${ }^{3,5,6}$. Although negative appendicectomy has negligible mortality, it has associated 10\% morbidity rate along with economic burden both on patients and our limited health resources. Previously accepted negative appendicectomy rate have recently been criticized because of risks and expense of unnecessary surgery ${ }^{7}$.

Therefore, diagnostic accuracy needs to be improved both for earlier diagnosis and for avoiding unnecessary appendicectomies. Of variously commonly used diagnostic aids for appendicitis like Computer tomography(CT scan ) Ultrasonography (USG) laparoscopy no single test can reduce negative appendicectomy rate to zero ${ }^{8}$.

USG has been reported to have excellent sensitivity and specificity with low cost ${ }^{9}$. However, patients 
factors and its operator dependant nature is a major drawback that leads many centers to use CT scan as the initial imaging study for acute appendicitis especially in atypical cases. CT scan has been reported to yield highest diagnostic accuracy ${ }^{10}$. Its main limitation is the non availability in most of our hospitals especially in remote areas.

Alvarado score is one of the scoring systems developed for efficient diagnosis of acute appendicitis in a cost effective manner. Alvarado score is simple, easy to apply, cheap diagnostic modality. It is based on history, clinical examination and few laboratory investigations. It is an objective assessment of right iliac fossa pain. It helps junior resident in order to decide whether to operate or not.

In our country most of the patients belong to low socioeconomic group who cannot afford latest costly investigations for diagnosing acute appendicitis which are being routinely used in western countries. So there is need to look for a investigation which should be cost effective, widely available, repeatable, free from operator dependence and more, over it must have high diagnostic accuracy. Alvarado scoring system fulfils this criteria and it reduces negative appendicectomy rate substantially thus leading to better utilization of our limited health resources.

Current study was conducted to determine the validity of Alvarado score in diagnosing acute appendicitis.

\section{PATIENTS AND METHODS}

90 consecutive clinically suspected cases of acute appendicitis admitted through emergency and outpatient department of Combined Military Hospital Rawalpindi were included in study between Oct 2009 to April 2009.

Patients of both gender and all age groups were included in the study after taking informed written consent. Patients with comorbids like diabetes mellitus, Ischemic heart disease, previous history of abdominal surgery, mass right iliac fossa were excluded from the study. All patients were evaluated by senior resident in surgery by taking detailed history and physical examination. Alvarado score was calculated by three senior resident and mean of the score was taken as definitive score. Baseline investigations like full blood count and routine urine analysis was carried out in all cases. All patients were divided into two groups on the basis of Alvarado score . Group I with score 7-10, Groupll was subdivided into two subgroups. Groupll (a) with 5-6 and Groupll (b) with $<4$ score. The decision to operate was taken by a consultant who was unaware of Alvarado score.

Patients from Group I were prepared for open appendicectomy after taking informed written consent. The resected appendix was sent to histopathology department of Armed Forces Institute of Pathology for histopathological examination. The criteria for histopathological diagnosis of acute appendicitis (gold standard) was based on the presence of neutrophils in the muscularis propria of the appendix. Histopathology of the appendix was correlated with Alvarado score.

Patients from Group II(a) were observed in hospital those who did not improve/ deteriorate(Alvarado score increased), underwent appendicectomoy. Patients from Group II(b) were discharged and they were advised to report back if their symptoms did not settle.

Data Analysis: Data was analyzed using SPSS version 15. Descriptive statistics were used to analyze the data. calculate mean, standard deviation for age and Alvarado score, frequencies and \% for gender and histopathology of appendix. 2x2 table was used to determine sensitivity, specificity, positive and negative predictive value of Alvarado score which was compared with histopathology of appendix keeping it as gold standard. 


\section{RESULTS}

Patients were included in this study, out of which $70(77.8 \%)$ male and 20(22.2\%) were female. The range of age was $13-50 \mathrm{yr}$ with mean age of 25.34 and standard deviation of 6.88. 61(67.8\%) patients had score 7 or $>7$ (Group I) and all underwent appendicectomy, histopathology confirmed appendicitis in 52(49 male and 3 female) and normal appendix in 9 ( 4 male and 5 female) cases.

10 out of 13 patients who scored 5-6 (Group II(a) also underwent appendectomy as their symptoms did not settle. Histopathology confirmed acute appendicitis in 7 (5 male/2 female) and normal appendix in 3 (3 female).

Group II (b) with score $<4$ were discharged and contacted 2-3 days after discharge and in all of them symptoms subsided without intervention. Alvarado score had overall $88.13 \%$ sensitivity $70.96 \%$ specificity $85.24 \%$ PPV and $75.86 \%$ NPV as given in table-l.

Whereas in male patients it had $90.74 \%$ sensitivity, 75\% specificity, $92.45 \%$ PPV and $70.58 \%$ NPV as given in table-II.

In female it had $60 \%$ sensitivity, $66.6 \%$ specificity, $37.5 \%$ PPV and $83.33 \%$ NPV as given in table-lll. The overall negative appendicectomy rate was $16.9 \%(6.89 \%$ in male, $38.46 \%$ in female) .

\section{DISCUSSION}

The hallmark of acute appendicitis is right iliac fossa pain until proven otherwise. It may simulate many other acute abdominal illnesses and prompt diagnosis is rewarded by a marked decrease in morbidity and mortality. Many methods have been investigated in order to reduce the negative appendicectomy rate and associated expenditures incurred due to it without increasing the perforation rate. However these methods have their own limitations such as USG is

\begin{tabular}{|l|c|c|c|c|}
\hline \multicolumn{2}{|c|}{} & \multicolumn{2}{|c|}{$\begin{array}{c}\text { Histopathology of } \\
\text { Appendix }\end{array}$} & \multirow{2}{*}{ Total } \\
\cline { 2 - 4 } \multicolumn{2}{|c|}{} & $\begin{array}{c}\text { Appendicitis } \\
(+)\end{array}$ & $\begin{array}{c}\text { Normal } \\
(-)\end{array}$ & \multicolumn{1}{|c}{} \\
\hline \multirow{2}{*}{$\begin{array}{l}\text { Alvarado } \\
\text { Score }\end{array}$} & $>7(+)$ & $52($ a) & $9($ b) & 61 \\
\cline { 2 - 5 } & $<7(-)$ & $7($ c) & $22($ d) & 29 \\
\hline Total & & 59 & 31 & 90 \\
\hline
\end{tabular}

Table-I. Alvarado score histopathology of appendix cross tabulation count

\begin{tabular}{|l|c|c|c|c|}
\hline \multicolumn{2}{|c|}{} & \multicolumn{2}{|c|}{$\begin{array}{c}\text { Histopathology of } \\
\text { Appendix }\end{array}$} & \multirow{2}{*}{ Total } \\
\cline { 2 - 4 } \multicolumn{2}{|c|}{} & $\begin{array}{c}\text { Appendicitis } \\
(+)\end{array}$ & $\begin{array}{c}\text { Normal } \\
(-)\end{array}$ & \multicolumn{1}{|c}{} \\
\hline \multirow{2}{*}{$\begin{array}{l}\text { Alvarado } \\
\text { Score }\end{array}$} & $>7(+)$ & $49($ a) & $4($ b) & 53 \\
\cline { 2 - 5 } & $<7(-)$ & $5($ c) & $12($ d) & 17 \\
\hline \multirow{2}{*}{ Total } & & 54 & 16 & 70 \\
\hline
\end{tabular}

Table-II. Alvarado score histopathology of appendix cross tabulation (male)

\begin{tabular}{|l|c|c|c|c|}
\hline \multicolumn{2}{|c|}{} & \multicolumn{2}{|c|}{$\begin{array}{c}\text { Histopathology of } \\
\text { Appendix }\end{array}$} & \multirow{2}{*}{ Total } \\
\cline { 2 - 4 } & $\begin{array}{c}\text { Appendicitis } \\
(+)\end{array}$ & $\begin{array}{c}\text { Normal } \\
(-)\end{array}$ & \\
\hline \multirow{2}{*}{$\begin{array}{l}\text { Alvarado } \\
\text { score }\end{array}$} & $>7(+)$ & $3($ a) & $5($ b) & 8 \\
\cline { 2 - 4 } & $<7(-)$ & $2($ (c) & $10($ d) & 12 \\
\hline Total & 5 & 15 & 20 \\
\hline \multicolumn{2}{|l|}{ Table-III. Alvarado score histopathology of appendix cross } \\
tabulation (female)
\end{tabular}

operator dependent, CT scan is expensive, laparoscopy is also expensive as well as invasive. Main drawback in our setup is that they are not available especially in remote areas where we use to serve due to military service requirement.

So there is a need to develop a diagnostic modality 
which should be accurate as well as cost effective, simple and readily available to emergency physicians in remote areas. Alvarado score is one of the many clinical scoring systems which have been developed to improve the diagnostic accuracy in acute appendicitis. It is simple, inexpensive, repeatable, and quick to apply in emergency room. Various studies have been done to determine the validity of Alvarado score in diagnosing acute appendicitis.

The current study was conducted at surgical department of CMH Rawalpindi in order to determine the validity of Alvarado score in diagnosing acute appendicitis. There were 90 patients in this study. Male to female ratio was $3.5: 1$ which shows it to be more common in male. Whereas literature shows slight preponderance in male patients i.e 1.4:11. The higher incidence in this study was due to the fact that there is less influx of female patients at CMH Rawalpindi as there is a separate female surgical department at $\mathrm{MH}$ Rawalpindi.

Acute appendicitis had highest incidence during 22-26 years which is in accordance with other studies ${ }^{12}$. The results of our study showed that the Alvarado score has $88.13 \%$ overall sensitivity $(90.74 \%$ in male, $60 \%$ in female) $70.16 \%$ specificity ( $75.45 \%$ in male, $66.66 \%$ in female) $85.24 \%$ PPV $(92.45 \%$ in male, $37.5 \%$ in female) $75.86 \%$ NPV $(70.58 \%$ in male , $83.33 \%$ in female) which is in accordance with other studies $^{12,13,14,15}$. Overall negative appendicectomy rate was $16.9 \%$ which is comparable with local as well as international studies ${ }^{3,12,15}$. $6.89 \%$ negative appendicetomy rate was observed in male which is in accordance with other studies. However in female patients it had negative appendicectomy rate $(38.46 \%)$ which is higher as compared with other studies. Its main reason was that female patients in our study may not represent true population due to less influx of female patients at CMH Rawalpindi.

Our results also showed that no patients with a score
$<4$ had acute appendicitis. In this study Alvarado score worked well in men as compared to women. In female patients, most commonly gynaecological problems mimic acute appendicitis. Therefore additional investigations like USG should be performed in order to improve the diagnostic accuracy. This has been cited by others as well ${ }^{13,14,16}$.

There are certain limitations in this study , there were less female patients that had effect on overall results of the study as this scoring system did not perform well infemale.

One main drawback of our study is that Alvarado score was not compared with histopathology in all cases. Ideally to see accurate validity of Alvarado score, every patient with suspicion of acute appendicitis should undergo appendicectomy so that Alvarado score can be compared with the gold standard(histopathology report). This also a limitation of most of other studies. Patients who are discharged, there is no absolute way to find whether they had acute appendicitis which resolved spontaneously except to have histopathology of resected appendix.

Therefore further studies should be carried out in future in which Alvarado score be compared with histopathology in all suspected cases of acute appendicitis to determine its accurate validity. Our study revealed that Alvarado score is very accurate for diagnosing acute appendicitis especially in male. As it is cost effective it will lead to better utilization of our limited health resources.

\section{CONCLUSIONS}

Alvarado score is very accurate for diagnosing acute appendicitis in male patients especially in remote areas where latest investigations are not available. Patients with score $<4$ can safely be discharged home without further investigations. USG should be performed routinely in female patients in order to improve the diagnostic accuracy of Alvarado score. 


\section{Copyright@ 29 Aug, 2012.}

\section{REFERENCES}

1. Ditillo MF, Dziura JD, Rabinovici R. Is it safe to delay appendectomy in adults with acute appendicitis? Ann Surg.2006 Nov;244(5):656-60.

2 O'connell PR. The vermiform appendix. In:Williams NS, Bulstrode CJK, O'Connell PR,eds.Bailey and Love's short practice of surgery. $25^{\text {th }}$ ed. London: Arnold;2008:1204-18.

3. Khan I, Rehman A. Application of Alvarado scoring system in diagnosis of acute appendicitis. J Ayub Med Coll Abbottabad.2005:17:41-4.

4. Morrow SE, Newman KD. Current management of appendicitis. Seminars in Pediateric Surgey. 2007 Feb;16(1):34-40.

5. Harswick C, Uyenishi AA, Kordick MF, Chan SB. Clinical guidelines, computer tomography scan and negative appendicectomies: a case series. Am J Emerg Med. 2006 Jan; 24(1):68-72.

6. Khanzada TW, Samad A, Sushel C. Negative appendectomy rate: Can it be reduced? JLUMHS. 2009 Jan-Apr;8(1):19-22..

7 Flum DR, Koepsell T. The clinical and economic correlates of misdiagnosed appendicitis: nationwide analysis. Arch Surg. 2002 Jul;137(7):799-804

8. Shoshtari MHS, Askarpou S, Alamshah M, Elahi A. Diagnostic value of Quantitative CRP measurement in patients with acute appendicitis. Pak J Med Sci.2006 Jul- Sep;22(3):300-03.
9. Lee JH, Jeong YK, Park KB, Jeong AK, Hwang JC. Operator dependent techniques for graded compression sonography to detect the appendix and diagnose acute appendicitis. AJR Am J Reontgenol.2005 Jan; 184(1):91-7.

10. Hoecker CC, Billman GF. The utility of unenhanced computer tomography in appendicitis in children. $J$ Emerg Med. 2005 May;28(4):415-21.

11 Humes DJ, Simpson J. Acute appendicitis. BMJ.2006Sep;333:530-4.

12. Talukder DBI, Siddiq. Modified Alvarado scoring System in the diagnosis of acute appendicitis. JAFMC Bangl. 2009 Jun;5(1):18-20.

13. Oh BY, Kim KH, Lee RA, Chung SS. Diagnostic efficacy of the Alvarado score according to age in acute appendicitis. J Korean Surg Soc. 2010Feb;78(2):10005.

14. Baidy N, Rodrigues G, Rao A, Khan SA. Evaluation of Alvarado Score in Acute Appendicitis: A prospective Study. The Internet Journal of Surgery [serial online]. 2007[cited 2010 May25];9(1). Available from. www.ispub.com/ostia/index.php?mIFilePath.../alvarad $0 . x \mathrm{l}$

15. Singh K, Gupta S, Pargal P. Application of Alvarado scoring system in diagnosis of acute Appendicitis. JK Science. 2008 Apr-Jan; 10(2):84-6.

16. Mckay R, Shepherd J. The use of the clinical scoring system by Alvarado in the decision to perform computer tomography for acute appendicitis in ED. Am J Emerg Med. 2007 Jun;25(5):489-93.
AUTHOR(S):

1. DR. SHAFAQAT ALI

Graded Surgical Specialist

Department of Surgery

CMH Rawalpindi

2. DR. ZAKA ULLAH MALIK

Classified Surgical Specialist

MH, Rawalpindi

3. DR. M. MUTTAHHAR ASIM NIAZ

Classified Surgical Specialist

Chitral Scouts Hospital, Chitral

4. Dr. Naveed Ahmed

Graded Surgical Specialist

$\mathrm{CMH}$, Sakardu
Correspondence Address:

Maj. Shafqat Ali

71 Med Bn Kohat

daskolian@yahoo.com 